\title{
Métodos de controle químicos e físicos de Marchantia polymorpha
}

\section{Physical and chemical methods for the control of Marchantia polymorpha}

\author{
Rafael NAVAS ${ }^{1}$; Maria Renata Rocha PEREIRA²; Guilherme Sasso F. de SOUZA ${ }^{3}$; \\ Dagoberto MARTINS ${ }^{4}$ \\ ${ }^{1}$ Autor para correspondência - Engenheiro agrônomo MSc Ecologia Aplicada - ESALQ/USP, Professor \\ Faculdade de Tecnologia de Capão Bonito, FATEC. Rua Amantino de Oliveira Ramos, 60 - Terras do \\ Embiruçú 18304-755 Capão Bonito/SP - 13418-900, e-mail: navas_rj@yahoo.com.br \\ ${ }^{2}$ Engenharia Florestal, Professora Faculdade de Tecnologia de Capão Bonito, FATEC, e-mail: \\ mariarenatarp@hotmail.com \\ ${ }^{3}$ Engenheiro agrônomo, doutorando FCA/UNESP, e-mail: guisasso@hotmail.com \\ ${ }^{4}$ Engenheiro agrônomo, Professor Livre Docente FCA/UNESP, e-mail: dmartins@fca.unesp.br
}

Recebido em: 03-09-2013; Aceito em: 18-03-2014

\begin{abstract}
Resumo
Marchantia polymorpha desenvolve-se em condições ambientais de alta umidade relativa do ar e sombreamento. Como esse habitat também é típico de viveiros para formação de mudas de espécies florestais nativas, a espécie desenvolve-se muito rapidamente entre as mudas em formação e causa prejuízos. A dificuldade de seu manejo motivou o desenvolvimento da pesquisa que objetivou estudar métodos químicos e físicos de controle. Foram realizados dois experimentos, ambos em viveiro de produção de mudas florestais nativas e em delineamento inteiramente casualizado, com quatro repetições. No primeiro, aplicaram-se sobre as plantas da espécie ácido acético (10, 20 e 40\%), água oxigenada $(50$ e $100 \%)$ e os herbicidas glyphosate $\left(1.680 \mathrm{~g} \mathrm{e}\right.$. a. ha $\left.{ }^{-1}\right)$ e fomesafen $\left(375 \mathrm{~g} \mathrm{i}\right.$. a. ha $\left.{ }^{-1}\right)$. No segundo, os tratamentos foram constituídos por solo previamente submetido a $105^{\circ} \mathrm{C}$, por 48 horas, solo submetido à solarização por plástico preto e transparente em pleno sol, por 30 dias, aplicação em pré-emergência de diuron $\left(1.750 \mathrm{~g}\right.$ i. a. ha $\left.{ }^{-1}\right)$ e trifluralina $\left(1.575 \mathrm{~g}\right.$ i. a. ha $\left.{ }^{-1}\right)$. As avaliações visuais de controle foram realizadas aos 7, 14, 21 e 28 dias após a aplicação (DAA) e aos 60 e 120 DAA, respectivamente, para o primeiro e segundo experimentos. Apenas os tratamentos com herbicidas diuron e trifluralina em aplicação de pré-emergência proporcionaram 100\% de controle aos 120 DAA.
\end{abstract}

Palavras-chave adicionais: desinfestação; eficiência de controle; hepática.

\begin{abstract}
Marchantia polymorpha develops under environmental conditions of high relative humidity and shading. As this habitat is the usually used in nurseries for the growth of seedlings of native tree species that species grows very quickly among developing tree seedlings and causes severe losses. This study was undertaken viewing more efficient either physical or chemical methods for the control of M. polymorpha. Two experiments were conducted under greenhouse conditions. In the first acetic acid (10, 20, and $40 \%$ of concentration), oxygenated water (50 and $100 \%$ ) and the herbicides glyphosate $(1,680 \mathrm{~g} \mathrm{Al} \mathrm{ha})$ and fomesafen ( $\left.375 \mathrm{~g} \mathrm{Al} \mathrm{ha}^{-1}\right)$ were applied to the seedlings. In the second, the treatments consisted of soil previously submitted to a temperature of $105{ }^{\circ} \mathrm{C}$ for 48 hours, soil submitted to solarization in black plastic and in transparent plastic bags for 30 days, preemergence application of diuron $\left(1,750 \mathrm{~g} \mathrm{Al} \mathrm{ha}^{-1}\right)$ and trifluralina $\left(1,575 \mathrm{~g} \mathrm{Al} \mathrm{ha}^{-1}\right)$. The visual evaluations of the methods were performed $7,14,21$, and 28 days after the application (DAA) and at 60 and 120 DAA, respectively, for the first and the second experiment. Only diuron and trifluralina resulted in a $100 \%$ control of M. polymorpha 120 DAA.
\end{abstract}

Additional keywords: control efficiency; disinfestations; liver.

\section{Introdução}

Nos viveiros de formação de mudas florestais, é constante a procura pela racionalização de custos e pelo melhoramento da qualidade das mudas produzidas, através do desenvolvimento de novas tecnologias (SILVA, 2008). Porém, no segmento florestal, os viveiros de produção de mudas estão permanentemente sujeitos a problemas que afetam de forma negativa a produtividade e a qualidade das mudas produzidas. As causas destes problemas são diversas, podendo ser de origem abiótica (geadas, chuvas de granizo e ventos) ou biológica, como a infestação por insetos, ocorrência de doenças e plantas daninhas como Marchantia polymorpha. 
A espécie descende de algas verdes (MARGULIS \& SCHWARTZ, 2001) e possui tecido condutor e cutícula pouco especializados (RAVEN et al., 1996), além de preferir ambientes com alta umidade e baixa luminosidade, condições estas também encontradas nos viveiros (SVENSON, 2000).

Marchantia polymorpha está dentre os problemas encontrados na produção de mudas nativas e exóticas, em casas de vegetação e viveiros de mudas, nos municípios de Ribeirão Grande e Capão Bonito- SP. Na região, a espécie tem acarretado consideráveis reduções no desenvolvimento, qualidade e valorização das mudas, devido à total ocupação da superfície do recipiente utilizado na produção. No processo competitivo, as sementes de espécies nativas não conseguem emergir, já que se forma uma barreira física, impedindo também a infiltração da água, prejudicando o desenvolvimento radicular das mudas (ALTLAND et al., 2011). Nos Estados Unidos, os mesmos prejuízos também foram encontrados pelos produtores (NEWBY, 2006).

RODRIGUES et al. (2007) comentaram que vasos com cultivo de plantas ornamentais que apresentam cobertura formada por briófitas possuem pouca ou nenhuma presença de mudas. Provavelmente, porque a germinação das plantas ornamentais é prejudicada pelas mudanças na amplitude de luz ou de temperatura ou, ainda, por efeitos alelopáticos e até mesmo pela barreira física criada pelas briófitas (SILVA et al., 2006).

A inexistência de herbicidas registrados para esta espécie também é considerada um obstáculo para seu controle (NEWBY, 2006). Dentre as ações de controle efetuadas empiricamente pelos viveiristas, na região de Capão Bonito, encontram-se a aplicação do herbicida glyphosate, o uso de óleo quente, água a alta temperatura e, até mesmo, a utilização de lançachamas. Entretanto, métodos alternativos também podem ser utilizados para controle de plantas daninhas em viveiros, como a esterilização do substrato com o uso de autoclave; solarização do substrato com ou sem o uso de coletor solar (SINIGAGLIA et al., 2001); esterilização do solo pela aplicação de fogo direto; uso de fosfeto de alumínio como fumigante no substrato; PCNB (pentacloronitrobenzeno a 75\%) aplicado por meio de regas nos saquinhos com substrato; uso da formalina (ROYAL PHARMACEUTICAL SOCIETY OF GREAT BRITAIN, 1996); e o uso de solução de hipoclorito de sódio a $12 \%$ de cloro ativo aplicado ao substrato (MIRANDA et al., 2007). A água oxigenada pode promover efeito tóxico, com queimaduras e necrose nas folhas (NELSON \& GETSINGER, 2000).

Considerando os prejuízos causados por $M$. polymorpha na formação de mudas nativas e exóticas, e sua dificuldade de controle, objetivou-se avaliar os efeitos de métodos físicos e químicos em seu controle, em viveiros florestais.

\section{Material e métodos}

Os experimentos foram realizados em viveiro de produção de mudas florestais nativas, localizado a $728 \mathrm{~m}$ de altitude, com latitude 24으' $57^{\prime \prime}$ sul e longitude $48^{\circ} 21^{\prime} 55^{\prime \prime}$ oeste, clima Cwa, segundo a classificação de Köppen, caracterizado por inverno seco e verão quente, no município de Ribeirão Grande, São Paulo (Brasil). Os dois experimentos foram conduzidos entre os meses de setembro de 2011 e fevereiro de 2012, com temperaturas médias do ar de $11^{\circ} \mathrm{C}$ a $28 \stackrel{\circ}{\circ} \mathrm{C}$.

Inicialmente, coletou-se terra de textura argilosa $(50,4 \%$ de argila, $23,9 \%$ de areia e $25,7 \%$ de silte) que, após seca à sombra, foi peneirada em peneira de malha com $5 \mathrm{~mm}$ e utilizada no preenchimentos dos recipientes (sacos pretos de plástico para formação de mudas, cujo volume foi de $3 \mathrm{~L}$ ).

O viveiro possui área de $100 \mathrm{~m}^{2}$ em área plana, posição leste-oeste, coberto com sombrite $50 \%$, e produção de 70 espécies nativas da Mata Atlântica. Todas as espécies são produzidas em sacos de polietileno com capacidade de $3 \mathrm{~L}$ e postas ao chão e com irrigação diária. Os recipientes foram separados em dois grupos, que constituíram os experimentos 1 e 2 .

Os tratamentos foram escolhidos devido ao uso destes produtos para controle de outras espécies de plantas daninhas em viveiros florestais da região deste estudo, pois não há nenhum herbicida registrado no Brasil para o controle desta espécie.

Para o experimento 1 , os tratamentos foram constituídos pela testemunha (sem aplicação de qualquer princípio de controle); aplicação de ácido acético nas concentrações a 10, 20 e $40 \%$; aplicação de água oxigenada nas concentrações a 50 e $100 \%$; aplicação de glyphosate $\left(1.680 \mathrm{~g}\right.$ e.a. ha $\left.{ }^{-1}\right)$ da marca comercial Roundup $\AA$, e aplicação de fomesafen (375 g i.a. ha $\left.{ }^{-1}\right)$ da marca comercial Flex®. Nesse caso, esperaramse a emergência e o estabelecimento das plantas de $M$. polymorpha em todas as parcelas e procedeu-se à aplicação dos tratamentos em pósemergência. Por ocasião da aplicação dos tratamentos, observou-se que os recipientes estavam, em média, com $100 \%$ de cobertura de sua superfície proporcionada por M. polymorpha.

O experimento 2 foi constituído pelos seguintes tratamentos: testemunha (sem aplicação de qualquer princípio de controle); aplicação de calor seco (estufa a $105 \pm 2{ }^{\circ} \mathrm{C}$, por 48 horas); aplicação de solarização com sacos pretos de plástico e aplicação de solarização com sacos transparentes de plástico, independentemente; aplicação de diuron (1.750 g i.a. ha ${ }^{-1}$ ), marca 
comercial Nortox $500 \mathrm{SC} \circledast$; aplicação de trifluralina (1.575 g i.a. ha $\left.{ }^{-1}\right)$, marca comercial Trifluralina Nortox Gold®. Nesse caso, não se esperaram a emergência e o estabelecimento das plantas de $M$. polymorpha em todas as parcelas, e procedeu-se à aplicação dos tratamentos em pré-emergência.

Para a aplicação dos tratamentos químicos, foi utilizado pulverizador costal pressurizado, equipado com barra de aplicação contendo quatro pontas de pulverização tipo jato plano XR11002VS, que regulado a $200 \mathrm{kPa}$ proporcionou volume de calda de $200 \mathrm{~L} \mathrm{ha}^{-1}$. A aplicação foi iniciada às $8 \mathrm{~h}$ e finalizada às $10 \mathrm{~h}$ do dia 12-09-2011, e no período constatou-se ausência de vento, temperatura média do ar de $21^{\circ} \mathrm{C}$ e $80 \%$ de umidade relativa média do ar.

Os tratamentos de solarização do solo foram aplicados, utilizando-se de sacos de plástico de duas cores: um com sacos pretos e outro com sacos transparentes. Estes dois tratamentos foram deixados a pleno sol, durante 45 dias, conforme descrito por LOPES et al. (2000) e GHINI et al. (1994).

Foram realizadas avaliações visuais de controle de $M$. polymorpha aos 7, 14, 21 e 28 dias após a aplicação (DAA) no experimento $1 \mathrm{e}$ aos 60 e 120 DAA no experimento 2. As avaliações visuais foram realizadas por meio de escala de percentual de notas, na qual 0 (zero) correspondeu a nenhuma injúria demonstrada pelas plantas, e 100 (cem) à morte das plantas, segundo a SOCIEDADE BRASILEIRA DA ClÊNCIA DAS PLANTAS DANINHAS (1995).

$O$ delineamento utilizado foi o inteiramente casualizado para os dois experimentos, com quatro repetições, e os resultados de cada experimento foram submetidos, separadamente, à análise de variância, pelo teste " $F$ ", sendo as médias dos tratamentos comparadas pelo teste de Tukey, a 5\% de probabilidade.

\section{Resultados e discussão}

Experimento 1: Observou-se fitotoxidade aos 7 dias após a aplicação (DAA) em plantas sob aplicação do herbicida fomesafen (15,8\%), e ácido acético 40\% (14,5\%), não diferindo estatisticamente entre si, conforme apresentado na Tabela 2. Não foram verificados sintomas de fitointoxicação nas plantas tratadas com ácido acético a $10 \%$ e $20 \%$; e com a aplicação de água oxigenada e glyphosate, o controle foi de apenas $5 \%$. Aos 14 DAA, o maior controle foi observado nas plantas com aplicação do herbicida fomesafen, atingindo valores de até $48,8 \%$. Sua eficiência no controle foi maior por ser um herbicida de contato, diferentemente do glyfosate, que, por ser sistêmico e a briófita não possuir vasos condutores, proporcionou menor controle, explicando assim a ineficiência deste herbicida para o controle desta espécie, como já observado por viveiristas. Corroborando os resultados encontrados, Franco et al. (2008) observaram controle em média de $15 \%$ com a aplicação dos herbicidas glyphosate, paraquat, 2,4-D + picloram. Aos 21 DAA, os resultados da eficiência de controle foram menores, pois as plantas de Marchantia polymorpha regeneraram-se, não respondendo mais aos tratamentos. Os índices de injúrias na hepática chegaram a $0 \%$ na avaliação realizada aos 28 DAA em todos os tratamentos. Um dos fatores que podem ser considerados é que, além dos esporos, o esporângio maduro da M. polymorpha contém células alongadas, chamadas elatérios, que apresentam espessamentos de parede helicoidais e são higroscópicos, absorvendo umidade (RAVEN et al., 1996), que, nas condições de viveiro, é altamente relevante, fazendo com que houvesse a geração esporofítica e, consequentemente, sua regeneração.

Tabela 1 - Porcentagem de controle das plantas de Marchantia polymorpha submetidas à aplicação de tratamentos químicos, aos 7, 14, 21 e 28 dias após a aplicação (DAA). Percentage of control o $f$ Marchantia polymorpha seedlings submitted to chemical treatments 7, 14, 21, and $28 D A A$.

\begin{tabular}{|c|c|c|c|c|}
\hline \multirow{2}{*}{ Tratamentos } & \multicolumn{4}{|c|}{${ }^{(a)}$ Controle (\%) } \\
\hline & $7 \mathrm{DAA}$ & $14 \mathrm{DAA}$ & $21 \mathrm{DAA}$ & 28 DAA \\
\hline Testemunha & $0,0 \mathrm{c}$ & $0,0 \mathrm{c}$ & $0,0 \mathrm{c}$ & 0,0 \\
\hline Ácido acético $10 \%$ & $0,0 \mathrm{c}$ & $10,5 \mathrm{c}$ & $6,2 \mathrm{bc}$ & 0,0 \\
\hline Ácido acético $20 \%$ & $0,0 \mathrm{c}$ & $11,3 \mathrm{c}$ & $8,9 \mathrm{bc}$ & 0,0 \\
\hline Ácido acético 40\% & $14,5 \mathrm{a}$ & $30,0 \mathrm{~b}$ & $11,2 b c$ & 0,0 \\
\hline Água oxigenada 50\% & $5,0 \mathrm{~b}$ & $10,0 \mathrm{c}$ & $12,5 \mathrm{ab}$ & 0,0 \\
\hline Água oxigenada $100 \%$ & $5,0 \mathrm{~b}$ & $10,0 \mathrm{c}$ & $12,5 \mathrm{ab}$ & 0,0 \\
\hline Glyphosate ( 1.680 g e.a. ha $\left.{ }^{-1}\right)$ & $5,0 \mathrm{~b}$ & $35,0 a b$ & $15,0 a b$ & 0,0 \\
\hline Fomesafen $\left(375 \mathrm{~g}\right.$ i.a. ha $\left.{ }^{-1}\right)$ & $15,8 \mathrm{a}$ & $48,8 \mathrm{a}$ & $23,7 \mathrm{a}$ & 0,0 \\
\hline$F_{\text {tratamentos }}$ & $42,383^{* *}$ & $27,937^{\star *}$ & $6730^{* *}$ & - \\
\hline $\mathrm{CV}(\%)$ & 34,2 & 32,21 & 47,14 & - \\
\hline
\end{tabular}

(a) Médias seguidas das mesmas letras minúsculas na coluna não diferem estatisticamente entre si, pelo teste de Tukey $(p<0,05)$; ${ }^{(b)}$ d.m.s. - diferença mínima significativa para $5 \%$ de probabilidade, pelo teste de Tukey. ${ }^{* *}$ Significativo ao nível de $1 \%$ de probabilidade, pelo teste F. 
Experimento 2: Até os 60 DAA não foi verificada a ocorrência de plantas de $M$. polymorpha em nenhum dos tratamentos estudados. Este fato pode ser devido às características da própria espécie e do clima, já que as temperaturas mínimas neste período foram abaixo da média registrada $\left(11^{\circ} \mathrm{C}\right)$. $\mathrm{Na}$ avaliação aos 120 DAA, observou-se excelente controle proporcionado pelos herbicidas diuron e trifluralina, com controle total das plantas (100\%), mesmo que estes herbicidas não sejam registrados no Brasil para esse fim (Tabela 2).

O uso da estufa (calor seco) e da solarização com plástico transparente mostrou-se ineficaz no controle das plantas de M. polymorpha. A solarização com plástico preto apresentou eficiência de controle de $39 \%$, sendo que este resultado não corrobora os de GHINI (1997), que recomendou o uso de plástico transparente por proporcionar maior eficiência de controle. Em outro trabalho sobre controle de tiririca, Ricci et al. (2006) registraram o controle de $86 \%$ das plantas com a utilização do plástico transparente na solarização.

Diante dos resultados obtidos, pode-se inferir que a aplicação de diuron e trifluralina em préemergência é uma alternativa para o controle desta briófita nos viveiros florestais. Outros estudos são necessários para avaliar o comportamento das espécies florestais nativas, produzidas nestes viveiros, aos herbicidas testados, já que cada espécie nativa terá um comportamento diferente a estes produtos, o que poderá contribuir para assegurar a produtividade e a valorização das mudas, bem como a qualidade e a integridade das mesmas.

Tabela 2 - Porcentagem de controle das plantas de Marchantia polymorpha submetidas à aplicação de diferentes tratamentos no solo, aos 120 dias após a aplicação (DAA). Percentage of controlo $f$ Marchantia polymorpha seedlings growing in soil submitted to different treatments 120 DAA .

\begin{tabular}{lc}
\hline \multicolumn{1}{c}{ Tratamentos } & ${ }^{(a)}$ Controle (\%) \\
\hline Testemunha & $0,0 \mathrm{c}$ \\
Solarização em saco preto de plástico & $39,0 \mathrm{~b}$ \\
Solarização em saco transparente de plástico & $7,5 \mathrm{c}$ \\
Calor seco $\left(105 \pm 2{ }^{\circ} \mathrm{C}-48 \mathrm{~h}\right)$ & $0,0 \mathrm{c}$ \\
Diuron $\left(1.750 \mathrm{~g}\right.$ i.a. ha $\left.^{-1}\right)$ & $100,0 \mathrm{a}$ \\
Trifluralina $\left(1.575 \mathrm{~g}\right.$ i.a. $\left.\mathrm{ha}^{-1}\right)$ & $100,0 \mathrm{a}$ \\
\hline $\mathrm{F}$ tratamentos & $561,357^{* *}$ \\
$\mathrm{CV}(\%)$ & 9,84 \\
\hline${ }^{(b)}$ d.m.s & 9,0 \\
\hline
\end{tabular}

(a) Médias seguidas das mesmas letras minúsculas na coluna não diferem estatisticamente entre si, pelo teste de Tukey $(p<0,05) ;{ }^{(b)}$ d.m.s. - diferença mínima significativa para $5 \%$ de probabilidade, pelo teste de Tukey. ${ }^{* *}-$ Significativo ao nível de $1 \%$ de probabilidade, pelo teste $\mathrm{F}$.

\section{Conclusões}

Os tratamentos químicos na planta com ácido acético, água oxigenada, glyphosate e fomesafen, e físicos no solo com calor seco e solarização não proporcionaram níveis satisfatórios de controle para Marchantia polymorpha. Somente os herbicidas diuron ( $1.750 \mathrm{~g}$ i.a. ha $\left.{ }^{-1}\right) \mathrm{e}$ trifluralin (1.575 g i.a. ha $\left.{ }^{-1}\right)$, em aplicação de pré-emergência, apresentaram $100 \%$ de eficiência no controle de M. polymorpha.

\section{Referências}

ALTLAND, J. E.; WEHTJE, G.; SIBLEY, J.; MILLER, M. E.; GILLIAM, C. H.; KRAUSE, C. Differential response of liverwort (Marchantia polymorpha) tissue to postapplied quinoclamine. Weed Technology, Washington, v.25, n.4, p.580-585, 2011.
GHINI, R.; PARAÍBA, L. C.; LIMA, M. W. P. Determinação de período para solarização do solo na região de Campinas/SP. Summa Phytopathologica, Botucatu, v.20, n.2, p.131133, 1994.

GHINI, R. Desinfestação do solo com o uso de energia solar: solarização e coletor solar. Jaguariúna: Embrapa-CNPMA, 1997. 29p. (Circular Técnica, 1).

LOPES, M. E. B. M.; GHINI, R.; TESSARIOLI, J.; PATRícIO, F. R. A. Solarização do solo para o controle de Pythium na cultura do pepino em cultivo protegido. Summa Phytopathologica, Botucatu, v.26, n.2, p.224-227, 2000.

MARGULIS, L.; SCHWARTZ, K. V. Cinco reinos: um guia ilustrado dos Filos da vida na Terra. 3.ed. Rio de Janeiro: Guanabara Koogan, 2001. cap.5, p.384-385. 
MIRANDA. G. R. B.; GUIMARÃES, R. J.; CAMPOS, V. P.; BOTREL, E. P.; ALMEIDA, G. R. R.; GONZALEZ, R. G. Métodos alternativos de desinfestação de plantas invasoras em substratos para formação de mudas de cafeeiro (Coffea arabica L.). Coffee Science, Lavras, v.2, n.2, p.168-174, 2007.

NELSON, L. S.; GETSINGER, K. D. Herbicide evaluation for control of wild taro. Journal of Aquatic Plant Management, Vicksburg, v.38, p.70-72, 2000.

NEWBY, A. F. Liverwort Control in ContainerGrown Nursery Crops. 2006. 80f. Dissertação (Mestrado em Ciências) - Auburn University, Auburn, 2006.

RAVEN, P. H.; EVERT, R. F.; EICHHORN, S. E. Biologia vegetal. 5.ed. Rio de Janeiro: Guanabara Koogan, 1996. cap.15, p.277-283.

RICCI, M. S. F.; OLIVEIRA, F. F.; MIRANDA, S. C.; COSTA, J. R. Produção de cenoura e efeito na fertilidade do solo e nutrição decorrente da solarização do solo para controle de tiririca. Bragantia, Campinas, v.65, n.4, p.607-614, 2006.

RODRIGUES, I. M. C.; FERREIRA, F. A.; GROSSI, J. A. S.; BARBOSA, J. G.; PAULA, C. C.; REIS, M. R. Ocorrência de plantas daninhas no cultivo de bromélias. Planta Daninha, Viçosa, MG, v.25, n.4, p.727-733, 2007.
ROYAL PHARMACEUTICAL SOCIETY OF GREAT BRITAIN. Martindale: the extra pharmacopoeia. $31^{\text {th }}$ ed. London, 1996. 2739p.

SILVA, A. A.; FERREIRA, F. A.; FERREIRA, L. R.; SANTOS, J. B. Biologia de plantas daninhas. In: SILVA, A. A.; SILVA, J. F. Tópicos em manejo de plantas daninhas. Viçosa: Universidade Federal de Viçosa, 2006. 318p.

SILVA, P. H. M. Indicadores estatísticos sobre viveiros florestais no Brasil. Piracicaba: Instituto de Pesquisas e Estudos Florestais. 2008. Disponível em: <http://www.ipef.br/silvicultura/indicadores.asp>. Acesso em: 21 jan. 2010.

SINIGAGLIA, C.; PATRICIO, F. R. A.; GHINI, R.; MALAVOLTA, V. M. A.; TESSARIOLI, J.; FREITAS, S. S. Controle de Sclerotinia minor, Rhizoctonia solani e plantas daninhas em alface pela solarização do solo e sua integração com controle químico. Summa Phytopathologica, Botucatu, v.27, p.229-235, 2001.

SOCIEDADE BRASILEIRA DA CIÊNCIA DAS PLANTAS DANINHAS. Procedimentos para instalação, avaliação e análise de experimentos com herbicidas. Londrina, 1995. 42p.

SVENSON, S. Control of liverworts and mosses in greenhouses. Aurora: Oregon State University, 2000. Disponível em: $<$ http://bryophytes.science.oregonstate.edu/page 24.htm >. Acesso em: 25 out. 2012. 